\title{
Factors affecting patients' self-management in chronic venous disorders: a single-center study
}

\author{
This article was published in the following Dove Press journal: \\ Patient Preference and Adherence \\ 24 August 2016 \\ Number of times this article has been viewed
}

\section{Kamil Barański ${ }^{1,2}$ \\ Jerzy Chudek ${ }^{2,3}$}

'Department of Epidemiology, Medical School in Katowice, ${ }^{2}$ Department of Pathophysiology, Medical University of Silesia, Katowice, ${ }^{3}$ Angiology Outpatient Clinic "Combi-Med," Częstochowa, Poland
Correspondence: Jerzy Chudek Department of Pathophysiology, Medical University of Silesia, Medyków Street I8, 40-752 Katowice, Poland Tel/fax +48 322528538 Email chj@poczta.fm
Background: The conservative treatment of chronic venous disorders (CVDs) includes pharmacotherapy, compression therapy, physiotherapy, and changes in lifestyle. These methods are available without prescription and not reimbursed by Polish National Health Service. Adherence to therapy is affected by poorly characterized patient-related factors.

Objective: The aim of the study was to perform an assessment of factors that affect the usage and resignation from conservative methods in CVD self-management.

Methods: A structured interview concerning self-management was carried out with 407 consecutive CVD patients of mean age 64.4 years (range: $23-87$ years). All the patients had recently undergone Doppler examination and were classified in accordance with Clinical, Etiology, Anatomy, and Pathophysiology (CEAP) classification.

Results: Pharmacotherapy was the most frequently ( $85.0 \%$ of respondents) used method in CVD self-management. Obese (odds ratio $[\mathrm{OR}]=1.75$ [95\% confidence interval $\{\mathrm{CI}\}$ 0.99-3.05]) and subjects with longer duration of the disease $(\mathrm{OR}=1.74$ [95\% CI 1.16-2.62]) were more likely to use venoactive drugs, while females used ointments commonly containing heparin ( $\mathrm{OR}=1.82[95 \%$ CI 1.08-3.03]). Compression therapy was perceived by respondents as the most difficult method in self-management ( $\mathrm{OR}=2.50$ [95\% CI 1.61-3.88]) and was also recognized as the most effective method of treatment ( $\mathrm{OR}=13.9$ [95\% CI 7.35-26.4]). Longer duration of CVD ( $\geq 15$ years) increased $(\mathrm{OR}=1.78[95 \% \mathrm{CI} 1.16-2.71])$ while obesity decreased $(\mathrm{OR}=0.38[95 \% \mathrm{CI} 0.20-0.72])$ the utilization of compression therapy. Females were more likely to adhere to lifestyle changes than males ( $\mathrm{OR}=1.68$ [95\% CI 0.97-2.90]). Physiotherapy was rarely used by the patients.

Conclusion: Obesity and longer duration of CVDs increase the use of venoactive drugs. Subjects with longer duration of the disease and without obesity are more likely to utilize compression therapy, the method considered to be the most effective but difficult in CVD self-management. Females are more prone to lifestyle changes and the use of heparin-containing ointments. There is an unmet need for health promotion regarding available CVD treatment methods and proper weight control measures to support CVD self-management.

Keywords: chronic venous disease, compression therapy, pharmacotherapy, lifestyle change, compliance

\section{Introduction}

Pharmacotherapy (the use of venoactive drugs [VADs]), compression therapy, physiotherapy, and changes in lifestyle are well-recognized methods of supportive therapy in chronic venous disorders (CVDs), as recommended by phlebologists and phlebological societies. ${ }^{1}$

The most valuable physical activity in CVD patients seems to be walking, which reduces sensation of tension in the shin area and increases lymphatic edema resorption. Lifestyle changes include leg elevation at night. ${ }^{1-4}$ Physiotherapy is recommended only 
in advanced CVD stages $\left(\mathrm{C}_{3}-\mathrm{C}_{6}\right)$ excluding patients with postthrombosis syndrome and varicose vein recurrence. ${ }^{2,3}$ Changes in both lifestyle and physiotherapy activate the muscle pump of the calf by strengthening the muscle and improving the ankle range of motion. ${ }^{5}$

Compression therapy that prevents superficial vessel extension and forces fluid from the interstitial spaces back into the vascular and lymphatic compartments is the most effective method in all CVD stages according to Clinical, Etiology, Anatomy, and Pathophysiology (CEAP) classification. ${ }^{6}$ Recognition of the disease at lowest stages $\left(\mathrm{C}_{0}\right.$ and $\mathrm{C}_{1}$ ), based on symptoms and telangiectasias, reduces discomfort, pain, and leg fatigue. ${ }^{7,8}$ In patients with varicose veins ( stage $\mathrm{C}_{2}$ ), identifying the disease at an early stage additionally prevents trophic changes and bleeding from varices. In more advance stages $\left(\mathrm{C}_{3}-\mathrm{C}_{6}\right)$, compression therapy reduces edema, accelerates venous ulcer healing, and prevents their recurrence. ${ }^{9,10}$ Systematic use of compression therapy plays a key role in the self-management of CVD patients., ${ }^{9,10}$

VADs are effective, safe, and available without prescription (over-the-counter [OTC]). However, these drugs are not entirely free of adverse drug reactions, which are however rare and not serious (eg, nausea, vomiting and diarrhea, urticaria, rash, headache, dizziness, and dry skin). ${ }^{11}$ VADs increase venous wall tonus and reduce capillary permeability, ${ }^{12-14}$ prevent the induction of inflammation, ${ }^{15-17}$ and increase lymphatic drainage ${ }^{18,19}$ as well as protect the microcirculation.

In fact, the broad range of supportive CVD therapies can be used even without consultation with general practitioner (GP) or phlebologist and can be applied after reading manuals and information given by specialists on websites. Furthermore, none of the therapies are reimbursed by Polish National Health Service and none necessitate prescription. Therefore, CVD self-management can be maintained without frequent consultations by specialists and GPs.

The aim of this study was to assess potential factors (including body weight status, education level, income, and perceived difficulty in application) that may influence taking or resignation from supportive therapy by patients in CVD self-management.

\section{Patients and methods}

A single-center study was conducted among 407 adult (aged $\geq 18$ years) CVD outpatients (334 females and 73 males) who had recently undergone (during the previous year) Doppler examination and agreed to participate in the study. CVD was diagnosed according to CEAP classification ${ }^{6}$ by a single phlebologist (JC). The study was performed from
March 2013 to July 2014. The study and the study protocol were approved by the Bioethical Committee of Medical University Silesia (KNW/0022/KB1/152/12), and decided that patients' verbal consent is acceptable due to the nature of the study. All participants agreed to take part in the structured interview performed by a single investigator (KB).

A questionnaire to support the structured interview was developed for the purpose of this study and validated on the group of 40 patients not included in the analyzed group. Cronbach's $\alpha$ reached a satisfactory level of 0.7 for core questions in the questionnaire. The questionnaire included 40 questions in seven sections: 1) metric, 2) symptoms and CVD risk factors, 3) advantages and disadvantages of CVD self-management methods, 4) frequency and types of self-management methods used currently and in the past, 5) motivation for self-management in CVDs, 6) effectiveness of VADs, and 7) metrics for the physician (including CVD symptoms, CEAP classification, and comorbidities).

\section{Data analysis}

Obesity was diagnosed based on WHO criteria (body mass index $\geq 30 \mathrm{~kg} / \mathrm{m}^{2}$ ). Pharmacotherapy in CVD was defined as the daily, or almost daily, use of any VADs (tablets, capsules). Compression therapy included the use of compression stockings, socks, or bandages on daily or almost daily basis (excluding summer). Lifestyle change was considered as any regular physical activity (eg, walking, running, cycling, or swimming) or leg elevation (forced by feeling of "heavy legs") introduced after the CVD diagnosis. Physiotherapy included regular gymnastics, massage of the lower limbs, hydrotherapy, or kinesiotherapy recommended by physicians or physiotherapist; advice available in the free guidelines.

CVD duration was scored according to the mean value as $<15$ years and $\geq 15$ years.

\section{Statistical analysis}

Data are shown as mean and standard deviation for quantitative data or number and percentage for qualitative data. The prevalence of features in the subgroups was compared with $\chi^{2}$ test and $\chi^{2}$ test for trend. The differences between groups were analyzed by Mann-Whitney $U$-test or Student's $t$-test. The assessment of association between used methods and resignation from therapy was done with the logistic regression analysis (odds ratios [ORs] with 95\% confidence intervals [CIs]). All the results were considered to be statistically significant if the $P$-value was $<0.05$. Statistical analyses were performed using STATISTICA 10.0 PL (StatSoft Polska, Cracow, Poland) and SAS 9.2 (SAS Institute Inc., Cary, NC, USA) software. 


\section{Results}

A total of 407 patients with a mean age of 64.4 (range: $23-87$ years) and a median of 11 (interquartile range: 5-30) years of CVD history were included in the study ( $\mathrm{n}=334$ females and $n=73$ males) (Table 1). According to CEAP classification, $42 \%$ of the patients were diagnosed with telangiectasias and reticular veins $<3 \mathrm{~mm}\left(\mathrm{C}_{1}\right), 45 \%$ with varicose veins $\left(\mathrm{C}_{2}\right)$, and $13 \%$ with signs of venous insufficiency (mostly $\mathrm{C}_{3}$ ). Secondary causes (Es) were identified in $4 \%$ of patients; insufficiency involved mostly great saphenous vein $\left(\mathrm{A}_{2,3}[62 \%]\right)$ and perforator veins of the thigh $\left(\mathrm{A}_{12}[71 \%]\right)$. Venous reflux was diagnosed in $95 \%$ of patients. There were fewer subjects with venous insufficiency in younger ( $<65$ years) compared to older subgroups; however, the difference was not statistically significant $\left(C_{1}: 45 \%[n=15]\right.$ vs $41 \%[\mathrm{n}=155], \mathrm{C}_{2}: 52 \%$ [n=17] vs $45 \%$ [n=166], and $\mathrm{C}_{3-6}$ : $3 \%[\mathrm{n}=1]$ vs $14 \%[\mathrm{n}=53]$, respectively; $P=0.22$ for trend).

A history of surgical procedures for vein incompetence (mostly stripping of the great saphenous vein) included 125 patients $(31 \%)$

\section{Current therapy}

The most commonly used method was pharmacotherapy - the use of VADs ( $\mathrm{n}=344,85 \%)$ and heparin-containing ointments $(n=269,66 \%)-$ followed by lifestyle changes $(n=275,70 \%)$ and compression therapy $(n=171,44 \%)$. Physiotherapy was used by four patients only and therefore was not analyzed in detail. There were no differences between females and males with regard to the use of the methods of self-management

Table I Demographic and anthropometric characteristics of patients with CVD $(n=407)$

\begin{tabular}{|c|c|c|c|c|}
\hline Characteristics & Total & $\begin{array}{l}\text { Females } \\
(n=334)\end{array}$ & $\begin{array}{l}\text { Males } \\
(n=73)\end{array}$ & $P$-value* \\
\hline Age, years (mean $\pm S D)$ & $64.5 \pm 12.2$ & $64.8 \pm 11.8$ & $62.7 \pm 13.6$ & 0.2 \\
\hline \multicolumn{5}{|c|}{ Residence (\%) } \\
\hline City & 90 & 90 & 89 & \multirow[t]{2}{*}{0.6} \\
\hline Village & 10 & 10 & II & \\
\hline \multicolumn{5}{|l|}{ Education (\%) } \\
\hline Higher & 20 & 16 & 12 & \multirow[t]{4}{*}{0.1} \\
\hline Secondary & 46 & 46 & 42 & \\
\hline Vocational & 19 & 17 & 29 & \\
\hline Primary & 15 & 21 & 16 & \\
\hline \multicolumn{5}{|c|}{ Anthropometric measurement (mean $\pm \mathrm{SD}$ ) } \\
\hline Body mass $(\mathrm{kg})$ & $77.1 \pm 13.9$ & $75.0 \pm 12.7$ & $86.7 \pm 15.1$ & $<0.001$ \\
\hline BMI $\left(\mathrm{kg} / \mathrm{m}^{2}\right)$ & $28.7 \pm 4.5$ & $28.7 \pm 4.4$ & $28.6 \pm 4.4$ & 0.6 \\
\hline \multicolumn{5}{|c|}{ Body weight status by World Health Organization } \\
\hline Overweight (\%) & 45 & 43 & 53 & \multirow[t]{3}{*}{0.2} \\
\hline Obesity (\%) & 37 & 38 & 31 & \\
\hline Normal weight (\%) & 18 & 19 & 16 & \\
\hline
\end{tabular}

Note: *Mann-Whitney $U$-test, Student's $t$-test, $\chi^{2}$ test, and $\chi^{2}$ test for trend were used as appropriate.

Abbreviations: BMI, body mass index; CVD, chronic venous disorder; SD, standard deviation. (females: $\mathrm{n}=305$ [91\%], males: $\mathrm{n}=59$ [81\%], $P=0.008$; females: $\mathrm{n}=303$ [91\%], males: $\mathrm{n}=48$ [66\%], $P=0.001$; females: $\mathrm{n}=255$ [76\%], males: $\mathrm{n}=46$ [63\%], $P=0.01$, for pharmacotherapy, lifestyle changes, and compression therapy, respectively). Similarly, $87 \%(n=120)$ of the subjects with primary or vocational level of education and $83 \%(n=224)$ with secondary or higher education level used pharmacotherapy, 69\% $(n=95)$ and $67 \%(n=180)$ used lifestyle changes, and $47 \%(n=65)$ and $39 \%(n=106)$ used compression therapy. Patients spent an average of $€ 23.5$ a month on CVD self-management (eg, VADs, compression stockings, bandages).

\section{Patients' perception on advantages and disadvantages of self-management methods}

Patients mostly considered effectiveness, and a feeling of relief, as advantages of the methods of CVD self-management, while expenditure of time, costs, and feeling of discomfort were considered the disadvantages. The method perceived by patients as the most effective was compression therapy $(\mathrm{OR}=13.9[95 \%$ confidence intervals $\{\mathrm{CI}\} 7.35-26.4])$ followed by pharmacotherapy (OR $=6.10$ [95\% CI 3.85-9.64]). Pharmacotherapy was reported as the most expensive method (opinion of $60 \%$ respondents), while compression therapy as embarrassing by generating discomfort (opinion of $31.5 \%$ respondents). Only $8 \%$ of respondents stated that lifestyle changes are time-consuming methods.

\section{Pharmacotherapy}

Most of the patients $(n=344,85 \%)$ declared that the use of VADs is the most effective and the easiest method in CVD self-management. Inconvenience of pharmacotherapy was declared by 95 respondents (23\%).

The most common VADs (all available without prescription) such as diosmin/micronized purified flavonoid fraction (MPFF) and Ruscus aculeatus extracts were used more often by females than males $(\mathrm{n}=252[75 \%]$ vs $\mathrm{n}=34$ [47\%], $P<0.001$ and $\mathrm{n}=172$ [51\%] vs $\mathrm{n}=24$ [32\%], $P=0.002$, respectively). Subjects with longer duration of the disease and obesity were more likely to use VADs in self-management (Figure 1). Place of residence and level of education did not influence the use of VADs as a part of self-management.

Ointments are a specific type of pharmacotherapy used in CVDs. As many as 66\% ( $\mathrm{n}=269)$ of participants used ointments containing heparin and $4 \%(n=17)$ used other ointments. Subjects with longer duration of the disease, females, and those with higher level of education used ointments more frequently (Figure 2). 


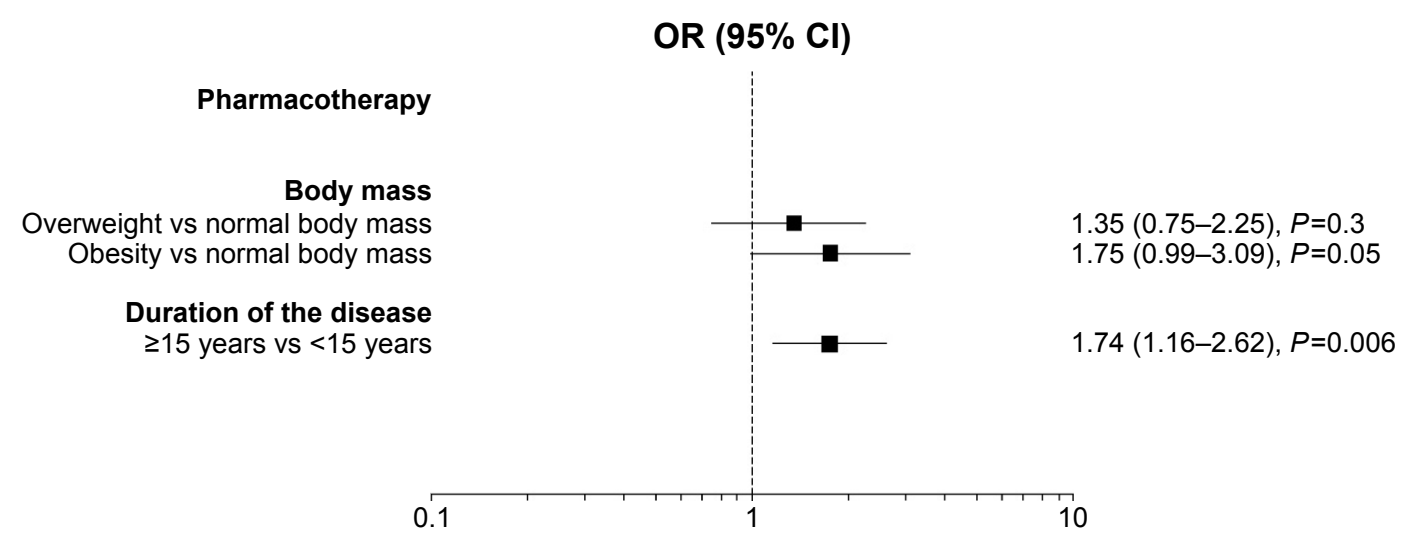

Figure I Factors influencing the use of venoactive drugs in patients with chronic venous disorder.

Abbreviations: $\mathrm{Cl}$, confidence interval; $\mathrm{OR}$, odds ratio.

\section{Lifestyle changes}

Lifestyle changes were considered as effective by $67 \%$ $(n=275)$ of the study participants. They were the second easiest method of self-management $(n=261,64 \%)$ and the least difficult method of relieving symptoms. There were six patients who had implemented lifestyle changes and had to abandon them because of the occurrence of pain, swelling, and muscle cramps. The most frequent physical activity was walking $(\mathrm{n}=239,58.7 \%)$, followed by bicycling $(n=65,15.9 \%)$ and swimming $(n=10,2.4 \%)$. A total of 365 respondents declared leg elevation during sleep was recommended by the specialist, while only 106 (25\%) declared the systematic use of this method. Results of the regression analysis showed that females are more likely to make lifestyle changes (OR $=1.68,95 \% \mathrm{CI} 0.97-2.90, P=0.06)$. Duration of the disease, body weight status, and level of education did not influence the taking or resignation from lifestyle changes.

\section{Compression therapy}

The reported disadvantages of compression therapy were: pain, tingling, lack of aesthetics, heat, and itching sensation. Compression therapy was perceived by $48.5 \%(\mathrm{n}=162)$ of females and $27.4 \%(n=20)$ of males as the most effort-requiring form of self-management $(P=0.001)$. Disadvantages of compression therapy were reported by 200 patients: feeling of heat ( $\mathrm{n}=73,36 \%)$; excessive compression $(\mathrm{n}=68,34 \%)$; itching $(n=29,14 \%)$; difficulty in applying the stockings $(n=24,12 \%)$; and others, such as discomfort, rolling, pain, and high cost (below 10\%). Approximately, $13.3 \%(\mathrm{n}=20$ ) of obese, $20.2 \%$ $(\mathrm{n}=37)$ of overweight, and $21.6 \%(\mathrm{n}=16)$ of respondents $(P=0.1)$ with normal body mass reported compression therapy as "too hot"; $14.6 \%(\mathrm{n}=22)$ vs $18.0 \%(\mathrm{n}=33)$ vs $17.5 \%(\mathrm{n}=13)$, $P=0.6$, reported excessive compression, while $3.3 \%(\mathrm{n}=5)$ vs $9.8 \%(\mathrm{n}=18)$ vs $8.1 \%(\mathrm{n}=6)$, respectively, $P=0.06$, reported itching. Difficulty in applying the stockings was reported by

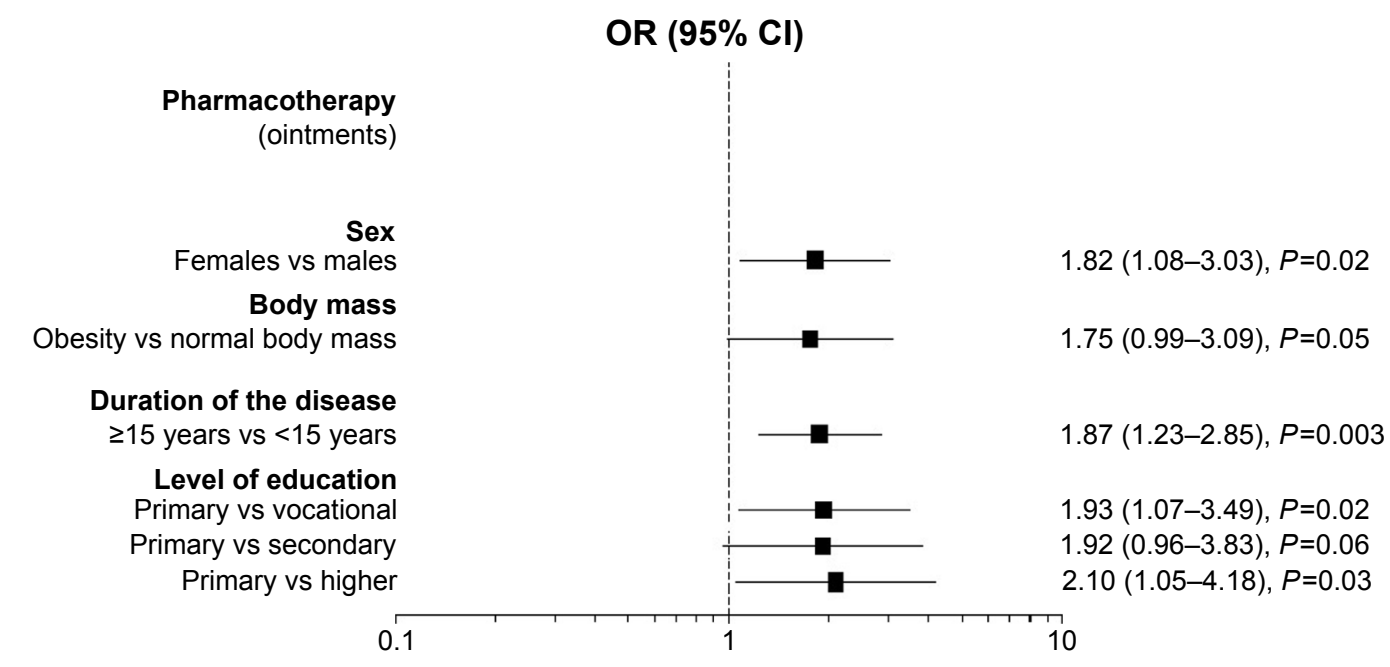

Figure 2 Factors influencing the use of pharmacotherapy with ointments only. Abbreviations: $\mathrm{Cl}$, confidence interval; OR, odds ratio. 


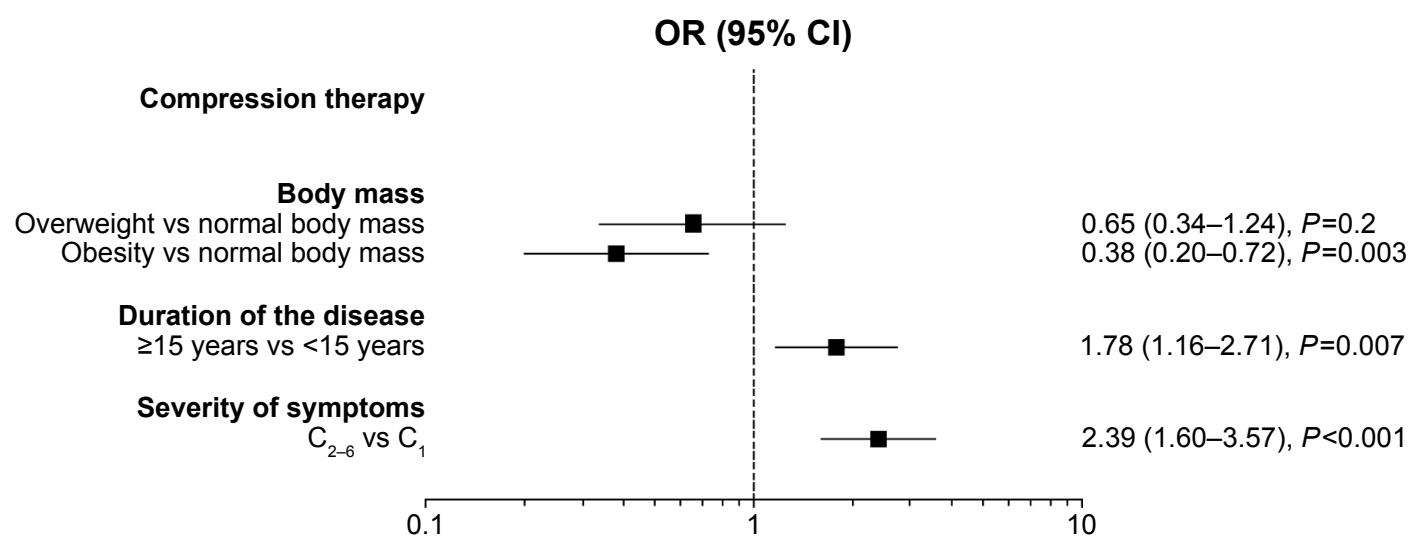

Figure 3 Factors influencing the use of compression therapy in patients with chronic venous disorder. Abbreviations: $\mathrm{Cl}$, confidence interval; OR, odds ratio.

$7.3 \%$ obese, $4.9 \%$ overweight, and $5.4 \%$ patients with normal body mass $(P=0.7)$. Other disadvantages that were reported were discomfort (4.6\% vs $3.2 \%$ vs $4.0 \%[P=0.9]$ ), rolling ( $2 \%$ vs $3.8 \%$ vs $1.3 \%[P=0.7])$, pain $(2.6 \%$ vs $2.7 \%$ vs $1.3 \%$ $[P=0.9])$, respectively. High cost of compression therapy was reported by newly diagnosed patients only.

Compression therapy was more frequently applied by $\mathrm{C}_{2}(\mathrm{n}=97,53 \%)$ and $\mathrm{C}_{3-6}(\mathrm{n}=26,48 \%)$ than $\mathrm{C}_{1}(\mathrm{n}=59,35 \%)$ subjects, $P<0.01$.

Logistic regression analysis showed that similar variables affected the rates of applying or not applying the compression therapy, as shown for pharmacotherapy (Figure 3).

\section{Discussion}

In this study, we have presented results on the factors influencing the three main methods of self-management used as supportive therapy in CVD patients: pharmacotherapy, lifestyle changes, and compression therapy.

Pharmacotherapy is the most frequent method used in the self-management by CVD patients. In this study, $84.5 \%$ of participants used VADs. Among the factors associated with taking OTC medicaments were body weight status and duration of the disease. This applies to the most popular medicaments such as diosmin/MPFF and R. aculeatus extracts. Participants of this study reported the use of VADs as highly effective and the least difficult. This method was more preferred by obese patients, probably due to lower adherence to compression therapy. This is in line with the results obtained in a previously conducted study in a large cohort of CVD patients which suggested that obese patients abandon compression therapy for pharmacotherapy because it is easier to use. ${ }^{20}$

Lifestyle changes were mainly interpreted by the study participants as physical activity (walking and bicycling), and only $26 \%$ of the respondents interpreted them as leg elevation, which actually relieves symptoms. The participants of this study did appreciate physical activity and perceived it as the effective method of self-management in CVDs. In our study, only females showed a borderline association with more frequent engaging in physical activity. This seems surprising, as in general females, especially older, are less active than males. ${ }^{21}$

Compression therapy is recognized as the only conservative method in CVD self-management that slows progression of the disease, ${ }^{22}$ but current publications contest the value of compression therapy due to insufficient data. ${ }^{23,24}$

In addition, compression therapy is perceived as inconvenient and doubtful in improving the quality of life. ${ }^{25}$ In this study, the factors associated with resignation from the use of compression therapy were obesity and shorter duration of the disease $(<15$ years). They are in line with those reported by the previously published studies. In a study performed by Cataldo et al, ${ }^{26}$ the main specific reasons for the resignation were the following: difficulty in applying the compression stockings (71.3\%), forgetting to wear (34.3\%), feeling hot in legs $(29.1 \%)$, dissatisfaction with the appearance of stockings $(15.3 \%)$, high price $(6.8 \%)$, increase in symptoms due to the use of compression therapy (1.3\%), and intensification of edema $(1.2 \%)$. In a study conducted by Raju et $\mathrm{a}^{27}$ on 3,144 subjects, $30 \%$ of participants were unable to specify a reason for not using compression, $25 \%$ of subjects reported that compression was not prescribed by the GP, and $14 \%$ mentioned that stockings were not effective. Few participants reported compression therapy as "too hot" $(8 \%)$, withdrawal from use because of poor cosmetic appearance $(2 \%)$, and contact dermatitis or itching (2\%). Surprisingly, only $2 \%$ claimed that they were unable to apply stockings without help (2\%). Furthermore, Shannon et $\mathrm{al}^{28}$ described, as reported by patients, difficulties in putting on (24\%) and removing (16\%) compression stockings, and pain when wearing (17\%). 
We have expanded the knowledge-concerning factors limiting the use of compression therapy. The results of our study show that obesity is the main reason for compression therapy abandonment. Obese participants less commonly used compression therapy than those with normal body weight ( $\mathrm{OR}=0.38$ ). This is probably due to difficulties in applying compression stockings. We expected that excessive compression and feeling of pain that may appear after applying inappropriate compression stockings may be the reason. However, excessive compression of similar frequency was reported by subjects across body weight statuses. Some other factors, not included in our study, should be mentioned. Stansal et $\mathrm{al}^{29}$ suggest that the main reason for resignation from compression therapy is the lack of appropriate training in application of compression bandages (45.4\%) and compression stockings (36.4\%).

Resignation from the use of compression therapy was not associated with sex and age. Results of our study confirm the previous findings in this area. ${ }^{26,27,30}$ However, it was related to CVD duration and severity of symptoms. Patients with varices or venous insufficiency $\left(\mathrm{C}_{2-6}\right)$ and longer duration of the disease used compression therapy more often. This is due to the worsening of symptoms along with the duration of CVD. ${ }^{27}$

Our study has some limitations. The mean time of the interview was $\sim 15$ minutes. Extending the interview for a longer time might increase the number of untrue answers. However, due to the older age of numerous participants, interview was probably a more reliable method than selfadministrated questionnaire. Another limitation of the study was overall duration of the study. End of the study period was at the beginning of spring. Higher temperatures could affect the compliance with compression stockings. In addition, an important limitation seems to be the lack of questions concerning the knowledge of self-management in CVD that might affect the perception of advantages and disadvantages of methods used in CVD self-management.

The strong side of this study was a structured interview that solved the problem of misunderstanding the questions. The study group was well characterized (all patients had undergone Doppler examination), reducing the chance for misclassification of CVD severity, and managed by a single phlebologist which made patients' counseling more homogeneous.

\section{Conclusion}

The results of this study show that patients with longer duration of the disease and without obesity are more likely to utilize compression therapy, the method considered as the most effective but most difficult to use in CVD selfmanagement. Obesity and longer duration of CVD increase the use of VADs. Females are more prone to lifestyle changes and use of ointments containing heparin. These factors should be taken into consideration when planning CVD treatment and patient counseling. There is an unmet need for health promotion regarding available CVD treatment methods and proper weight control measures to support CVD selfmanagement.

\section{Acknowledgments}

This study was fully funded by the authors of the study. The authors thank Mr Habib Arabzada for his invaluable editorial help during the preparation of this manuscript. This publication is part of Kamil Barański dissertation titled "Assessment of supportive therapy in chronic venous disorders."

\section{Disclosure}

The authors report no conflicts of interest in this work.

\section{References}

1. Padberg FT Jr, Johnston MV, Sisto SA. Structured exercise improves calf muscle pump function in chronic venous insufficiency: a randomized trial. J Vasc Surg. 2004;39(1):79-87.

2. Steins A, Junger M. Physical therapy in patients with chronic venous insufficiency. Phlebology. 2000;29:48-53.

3. Stick C, Jaeger H, Witzleb E. Measurements of volume changes and venous pressure in the human lower leg during walking and running. J Appl Physiol. 1992;72(6):2063-2068.

4. Yang D, Vandongen YK, Stacey MC. Effect of exercise on calf muscle pump function in patients with chronic venous disease. Br J Surg. 1999; 86(3):338-341.

5. Wittens C, Bækgaard N, Broholm R, et al. European Society for Vascular Surgery. Editor's choice - Management of chronic venous disease: clinical practice guidelines of the European Society for Vascular Surgery (ESVS). Eur J Vasc Endovasc Surg. 2015;49(6):678-737.

6. Eklof B, Rutherford RB, Bergan JJ, et al. Revision of the CEAP classification for chronic venous disorders: consensus statement. J Vasc Surg. 2004;40(6):1248-1252.

7. Weiss RA, Duffy D. Clinical benefits of lightweight compression: reduction of venous-related symptoms by ready-to-wear lightweight gradient compression hosiery. Dermatol Surg. 1999;25(9): 701-704.

8. Bengini JP, Sadoun S, Allaert FA, Vin F. Etude comparative de l'efficatite des chaussettes de compression de classe 1 sur la symptomatologie de la maladie veineuse chronique debutante [Comparative study of the effectiveness of class 1 compression stockings on the symptomatology of early chronic venous disease]. Phlebology. 2003;363:117-125. French.

9. Partsch H, Wingier J, Lun B. Compression stockings reduce occupational leg swelling. Dermatol Surg. 2004;30(5):737-743.

10. Diehm C, Trampisch HJ, Lange S, Schmidt C. Comparison of leg compression stocking and oral horse-chestnut seed extract therapy in patients with chronic venous insufficiency. Lancet. 1996;347(8997):292-294.

11. Ramelet AA, Perrin M, Kern P, Bounameaux H. Drug treatment of CVD. In: Ramelet AA, Perrin M, Kern P, Bounameaux H, editors. Phlebology. 5th ed. Issy-les-Moulineaux, France: Elsevier Masson; 2008: 269-334. 
12. Ibegbuna V, Nicolaides AN, Sowade O, Leon M, Geroulakos G. Venous elasticity after treatment with Daflon $500 \mathrm{mg}$. Angiology. 1997; 48(1):45-49.

13. Cospite M, Dominici A. Double-blind study of the pharmacodynamics and clinical activities of $5683 \mathrm{SE}$ in venous insufficiency. Advantages of the new micronized form. Int Angiol. 1989;8(4 Suppl):61-65.

14. Svensjö E, Bouskela E, Cyrino FZ, Bougaret S. Antipermeability effects of Cyclo 3 Fort in hamsters with moderate diabetes. Clin Hemorheol Microcirc. 1997;17(5):385-388.

15. Shoab SS, Porter JB, Scurr JH, Coleridge-Smith PD. Effect of oral micronized purified flavonoid fraction treatment on leukocyte adhesion molecule expression in patients with chronic venous disease: a pilot study. J Vasc Surg. 2000;31(3):456-461.

16. Huang YL, Kou JP, Ma L, Song JX, Yu BY. Possible mechanism of the anti-inflammatory activity of ruscogenin: role of intercellular adhesion molecule-1 and nuclear factor-kappaB. J Pharmacol Sci. 2008; 108(2):198-205.

17. Takase S, Lerond L, Bergan JJ, Schmid-Schönbein GW. The inflammatory reaction during venous hypertension in rats. Microcirculation. 2000;7(1):41-52.

18. McHale NG, Hollywood MA. Control of lymphatic pumping of Daflon $500 \mathrm{mg}$. Phlebology. 1994;9:23-25.

19. Bouskela E, Cyrino FZ, Marcelon G. Effects of Ruscus extract on the internal diameter of arterioles and venules of the hamster cheek pouch microcirculation. J Cardiovasc Pharmacol. 1993;22(2): 221-224.

20. Ziaja D, Kocełak P, Chudek J, Ziaja K. Compliance with compression stockings in patients with chronic venous disorders. Phlebology. 2011;26(8):353-360.
21. Lee YS. Gender differences in physical activity and walking among older adults. J Women Aging. 2005;17(1-2):55-70.

22. Motykie GD, Caprini JA, Arcelus JI, Reyna JJ, Overom E, Mokhtee D. Evaluation of therapeutic compression stockings in the treatment of chronic venous insufficiency. Dermatol Surg. 1999;25(2):116-120.

23. Lim CS, Davies AH. Graduated compression stockings. CMAJ. 2014;186(10):E391-E398.

24. Palfreyman SJ, Michaels JA. A systematic review of compression hosiery for uncomplicated varicose veins. Phlebology. 2009;24:13-33.

25. O’Meara S, Cullum N, Nelson EA, Dumville JC. Compression for venous leg ulcers. Cochrane Database Syst Rev. 2012;11:CD000265.

26. Cataldo JL, Pereira de Godoy JM, de Barros N. The use of compression stockings for venous disorders in Brazil. Phlebology. 2012;27(1): 33-37.

27. Raju S, Hollis K, Neglen P. Use of compression stockings in chronic venous disease: patient compliance and efficacy. Ann Vasc Surg. 2007; 21:790-795

28. Shannon MM, Hawk J, Navaroli L, Serena T. Factors affecting patient adherence to recommended measures for prevention of recurrent venous ulcers. J Wound Ostomy Continence Nurs. 2013;40(3):268-274.

29. Stansal A, Lazareth I, Michon Pasturel U, Ghaffari P, Boursier V, Bonhomme S. Compression therapy in 100 consecutive patients with venous leg ulcers. J Mal Vasc. 2013;38(4):252-258.

30. Jull AB, Mitchell N, Arroll J, et al. Factors influencing concordance with compression stockings after venous leg ulcer healing. J Wound Care. 2004;13(3):90-92.
Patient Preference and Adherence

\section{Publish your work in this journal}

Patient Preference and Adherence is an international, peer-reviewed, open access journal that focuses on the growing importance of patient preference and adherence throughout the therapeutic continuum. Patient satisfaction, acceptability, quality of life, compliance, persistence and their role in developing new therapeutic modalities and compounds to optimize

\section{Dovepress}

clinical outcomes for existing disease states are major areas of interest for the journal. This journal has been accepted for indexing on PubMed Central. The manuscript management system is completely online and includes a very quick and fair peer-review system, which is all easy to use. Visit http://www. dovepress.com/testimonials.php to read real quotes from published authors. 